\title{
Die doel van gemeentebou
}

M Nel

(Universiteit Vista)

\section{ABSTRACT}

The purpose of building up the local church

Building up the local church is driven by different motives. More often than not, these motives concern the survival of a specific church and/or denomination. Even Church Growth may be considered to be a motive of maintenance. It happens that, while churches grow in a given area Christianity declines in that same area. The purpose of Building up the Local Church has everything to do with the understanding of the church, with ecclesiology. On the other hand any preoccupation with ecclesiology may be a sign of decline in itself (Hoekendijk). The objective of this article is to focus or refocus the current discussions on ecclesiology and on Building up the Local Church on the purpose of this ministry as such. My contention is that this purpose is to be understood as missiological in essence.

\section{INLEIDING}

Gemeentebou is direk diensbaar aan die doel van God met die kerk op aarde ${ }^{1}$. Daar is verskeie redes waarom gemeentebou nodig is. Ten diepste is gemeentes betrokke by hulle eie opbou omdat God die opbou van die gemeente in diens van sy doel daarmee wil. Die vraag na die doel van hierdie bediening en betrokkenheid by dit wat Gód doen, vra voortdurende besinning. Gemeentebou is lank genoeg "op pad" om met veiligheid te beweer dat gemeentes nie altyd met dieselfde doel daarmee besig is nie, ongeag wat hulle motiewe daartoe is. Die teologie, en veral ekklesiologie, van plaaslike begeleiers van die proses informeer die motief en die doel van die proses. Eensydige beklemtonings was nog altyd in enige bediening 'n gevaar en so ook in gemeentebou. Die doel van hierdie artikel is om die voortgaande besinning in die ekklesiologie en gemeentebou opnuut te fokus op die verstaan van die doel van gemeentebou en wel as kontrole beginsel in hierdie bediening. Om dit in die taal van die nuwe klem in die onderwys van die land te sê: die doel is uitkoms gerigte gemeentebou en die kritiese vraag na wat die uitkoms(te) van gemeentebou is en behoort te wees. 


\subsection{Oorlewing en instandhouding}

Vernuwing in en van die kerk was nog altyd deel van die doel van hierdie bediening 2 . In meer as een geval word gemeentebou gesneller deur bepaalde probleme in 'n plaaslike gemeente en selfs denominasie. Vernuwing van die gemeente (as doel) hou gewoonlik hiermee verband ${ }^{3}$.

Dit is teologies moeilik om tegelyk die sentrale belang van die kerk en die relatiewe belang van die kerk vas te hou. Eensydigheid in hierdie verband kan dikwels langs die pad van die kerk se geskiedenis aangetoon word. In tye van krisis en bedreiging word die "beskerming", die bewaring en oorlewing van die kerk maklik tot doel van gemeentebou. Die bediening word 'n "kom ons red die kerk" poging.

In tradisionele kerke word hierdie doel van gemeentebou dikwels gesoek. Tydens die jeug rewolusie was dit ook die antwoord van die georganiseerde kerke op die "verdwyning" van die jeug uit die plaaslike gemeentes". Te Velde praat in hierdie verband tereg van "gemeenteopbouw als remedie tegen de leegloop van de kerken"s. Sommige plaaslike gemeentes raak slegs betrokke by gemeentebou as proses omdat hulle dink (soms onbewustelik) dat dit 'n "kom ons help die gemeente" projek is. Ek is persoonlik al by geleentheid as konsultant oor die hoof gesien "omdat hy van die gemeente 'n missionêre gemeente sal maak".

\subsection{Vernuwing as herlewing}

Die verband tussen hierdie beklemtoning en die herlewingsbeweging is opvallend. In eerlikheid word erken dat dit nie altyd in herlewingsbewegings so was en is nie. Laasgenoemde was dikwels gedryf deur egte besorgdheid oor die missionêre doel van die kerk.

Vernuwing as antwoord op die bepaalde probleem of probleme van 'n kerk word soms wel eensydig tot 'n behoefte aan herlewing vergeestelik. Die vraag word: hoe red ons die gemeente/denominasie eerder as waarom wil ons die gemeente help om te oorleef? Die nood van die kerk word met die doel van die kerk verwar. Die begeerte van die soekers van herlewing is dat dit weer met die gemeente "geestelik" goed mag gaan. Dit word 'n gebed dat dit weer met die gemeente mag gaan - soos "vroeër". Die vraag na die doel is in hierdie beweging dikwels vaag. Die model is ook meermale hoe dit met die vroeë kerk gegaan het sonder insig waarom dit met die vroeë kerk so "goed" gegaan het'. Die gemeente word soms vasgevang in die bose kringloop van die bekende herlewingsgebed: "do it again Lord". Die ervarings van 'n vroeëre heilstyd word die doel van die 
vernuwing. Gibbs is korrek wanneer hy stel dat die gemeente sò vasgevang word in die "blackhole" 7 . Vernuwing is in hierdie sin 'n kringloop. Periodieke herlewings (oplewings) en voortdurende her-organisering word die patroon. Die probleem word eensydig soteriologies geïnterpreteer en byna na die ewigheid verplaas.

Hierdie benadering tot "vernuwing" as die doel van gemeentebou is subtiel en aantreklik. Dit lei maklik tot 'n binnekerklike gesprek wat op niks anders uitloop as nog 'n oorlewingspoging nie. Indien König se boek nie 'n duidelike klimaks vind in wat hy 'n "sendingspiritualiteit" 8 noem nie, sou dit maklik as 'n "vernuwe of verdwyn" bydrae in bogenoemde sin as 'n "kom ons red die kerk" benadering tipeer kon word. 'n Pleit vir ruimteskepping' (soos byvoorbeeld openheid vir verskillende vorme van aanbidding) is ' $n$ noodsaaklike element van gemeente vernuwing, maar doel van gemeentebou is dit nog nie. Dit is weliswaar ook nie König se bedoeling nie.

Bogenoemde verstaan van vernuwing mislei gemeentes om vasgevang te word in hulleself. Die gemeente en hoe dit "geestelik" met hulle gaan, word sodoende die doel van gemeentebou. Dit gaan goed omdat dit met ons goed gaan, soms sonder genoegsame kritiese bewussyn of vraag na die waarom en waartoe die gemeente bestaan. In die meeste gevalle gaan dit ook slegs maar funksioneel en struktureel goed.

\subsection{Opvallende tendense}

Enkele opvallende tendense wat met hierdie eensydigheid saamgaan, is die volgende:

* die beklemtoning van die kerk as doel van God met die verlossingsplan in Christus.

* die teologiese rasionalisering van die denominasionele identiteit van die bepaalde gemeente - die "ons is reg" sindroom.

* die eensydige klem op die ewige lewe as doel van die verlossing.

* 'n gebrekkige Koninkryk bewussyn en perspektief asook 'n verstaan van die kerk as dienskneg in die koms van die Koninkryk.

\subsection{Kerk groei}

Sonder om die totale "church growth" beweging hierby te impliseer, is dit meermale die swakheid van die beweging. Solank die gemeente groei, 
word die vraag selde gevra of die Christendom groei. Gewoonlik is groei ook nie missionêr te verstaan nie, maar "groei in getalle". Callahan se keuse vir die begrip "mission growth" is in hierdie verband veelseggend: "God calls us to grow the mission... We do the mission for the integrity of the mission"10. Om 'n lastige gewete stil te maak, word kerkgroei dikwels as "oorkom na die regte kerk" gemotiveer. Groei word teologies gerasionaliseer en dit word niks anders as die herrangskikking van die stoele op die dek nie - of soos daar soms in die spreektaal in die VSA daarna verwys word as "the circulation of the saints". Dit gebeur selfs dat gemeentes groei terwyl die Christendom kwyn ${ }^{11}$. Binne so 'n benadering verword die "red die kerk" poging tot "die oorlewing van die grootste". "Groot is goed" word die slaapmiddel vir lidmate wat soms nog wonder oor wie nou eintlik wen in hierdie "oorlog om die 'siel' van ander gemeentes/kerke se lidmate". Hiermee word nie bedoel dat alle verwisseling van gemeente of kerk sò gemotiveer is nie. Soms verloor gemeentes juis lidmate omdat die vraag na doelgerigte funksionering net nie in hulle tuisgemeente gevra word en geld nie. Soms is die kern van gemeentes siek en lidmate gaan om ernstige redes weg na ander gemeentes van dieselfde denominasie of na ander kerke.

"Kom ons red die kerk" verword ook maklik tot "kom ons plant die kerk". Dit word die motief vir die "sending" van die kerk. Soveel so dat wanneer die "sendingkerk" dan nie meer handel soos die een wat geplant het nie, word die "nuwe kerk" onder vraagteken geplaas. Koloniale uitbreiding van die kerk sedert Konstantyn ly al aan hierdie siekte toestand. Wanneer die "kerk wat reg is" saam met die "een wat mag het" kom, kry die uitbreiding van die Christendom seer ${ }^{12}$. Talle gemeentes het nou nog nie van hierdie "van bo af" benadering afgeklim nie. Talle evangelisasie metodes vertoon hierdie reste van "die wat beter weet en met gesag kom" 13. Motief en doel is hier so fyn verweef dat dit soms moeilik is om te onderskei tussen geldige uitreik na die buitekerklike wêreld en gekamoefleerde "kom ons red die kerk" pogings. Instandhouding kom inderdaad op baie maniere na vore.

\subsection{Independentisme}

Nog so ' $n$ misverstand is die dreigende independentisme wat met hierdie doel saamgaan. Wanneer die "kom ons red die kerk veldtog" met teologiese rasionalisering saamgaan is die independentisme in sy kiem teenwoordig. 'n Onderwaardering vir die eenheid van die kerk is hier opvallend. Independente kerke vind redes waarom hulle nie verder binne die verband van hulle denominasie God kan dien nie. Hulle red die bepaalde 
gemeente van die kerk. Die "kerk" vind verlossing van die kerk. In uiterste gevalle van deformasie sou so 'n reformasie gerasionaliseer kon word. In die gees van die reformasie behoort "wegbreek" 'n laaste uitweg te wees. Niemand sou egter kon beweer dat daar nie so 'n oomblik in die lewe van 'n gemeente kan aanbreek nie. Tog is my indruk dat dit selde of ooit die motief by die wegbreek van independente gemeentes was nie. Die independentisme is gewoonlik 'n te gemaklike poging om die gemeente te red van die kerk. Die "moeder" word meermale in die stryd om reformasie te gou "dood" verklaar en as "nie reformeerbaar" prysgegee. In watter mate die Ned Geref Kerk byvoorbeeld tans aan hierdie "gees van independentisme" blootgestel is, verg 'n empiriese studie op sy eie.

\section{ROEPINGSVERVULLING AS DOEL}

\subsection{Identiteit en doel}

Verantwoorde vernuwing is in gemeentebou van kritiese belang. Die vraag is met watter motief, met watter doel en met watter teologie dit aangepak word. In hierdie verband is die verstaan van die gemeente se identiteit die kontrole prinsipe in die opbou van die gemeente ${ }^{14}$. Dit is nie moontlik om identiteit en doel in gemeentebou te skei nie. Die doel van die gemeente is met die identiteit en die verstaan daarvan aan die gemeente gegee. Soos identiteit is die doel van die gemeente deel van die indikatief. God skenk die doel waartoe $\mathrm{Hy}$ die kerk roep. God vra wat $\mathrm{Hy}$ gegee het ${ }^{15}$. Anders gestel sou gesê kan word dat die roeping van die kerk (soos wat dit uit sy identiteit voortvloei) ook die doel van die kerk is.

Gemeentebou is niks anders as identiteitsverstaan en -vinding nie ${ }^{16}$. Dit is tegelyk die teologiese eenvoud en teologiese kompleksiteit van gemeentebou. Dat gemeentebou niks meer as dit is nie, is 'n troos. Dat dit ook niks minder as dit is nie is "skrikwekkend". Die metaforiese spreke van die Skrif oor die identiteit van die kerk is in hierdie verband ook beide troos en angs. Dat die gemeente byvoorbeeld "die kudde" van God is, maak die verstaan van die gemeente (sy identiteit) vir kinders toeganklik. Dat die gemeente nie maar net "kudde" is nie, maar ook bruid, liggaam, volk, huisgesin, ensovoorts, maak die gemeente onoorsigtelik (in die sin van onder volle verstaan bring) en 'n saak van geloof.

\section{Die kerk as geskenk van God aan die wêreld}

Daar lê egter 'n primêre verstaan van die kerk agter alle metafore. Ek noem dit graag: die kerk (in sy metaforiese veelsydigheid) as geskenk van God aan die wêreld. Om dit nog eens metafories te sê: Dit is hierdie 
verstaansraam wat die metafories-dimensionele verstaan van die kerk afrond soos 'n goeie raam 'n mooi skildery. Verstaan van roeping en doel het alles te doen met hierdie primêre insig in die wese van die kerk. Metaforiese verstaan van die kerk alleen en opsigself (sonder 'n ekklesiologiese raam) het selfs al daartoe gelei dat van metafore vir die gemeentemodelle vir die gemeente en sy funksionering gemaak is. Metaforiese identiteitvinding bly slegs heilsaam vir die gemeente en relevant vir die wêreld binne ' $n$ trinitariese verstaansraam van die kerk as sodanig. Die kerk is die beweging van God Drie-enig. Die kerk is een van die unieke, deur Hom gekose, maniere waarop Hy na die wêreld kom ${ }^{17}$.

Om dit nog 'n keer anders te sê: die verstaan van die kerk in die Nuwe Testament (as herskepte mense van God) mag nie losgemaak word van die teologie van die skepping nie ${ }^{18}$. God herskep (in Christus) geskape mense. Die God wat herskep, het geskep. Dit is nie iemand anders se maksel wat oorgemaak word nie, dit is God se eiendom wat tot verstaan van hulle eiendomlikheid kom. Die kerk as nuwe mensheid is slegs te verstaan binne die verstaan van God se skeppingshandelinge met sy mense. Ons word in 'n sin nie nuut geskep nie, maar teruggeskep tot ons oorspronklike bedoeling. Die kerk ontdek sy doel in God se bedoeling met die mens.

\subsection{Missionêre identiteit}

Die primêre vraag binne die besinning oor die doel van gemeentebou is die vraag na die roeping en doel van die kerk. Hierdie soek na identiteit vind altyd kontekstueel plaas. Die antwoord op die vraag sal altyd 'n kontekstuele antwoord wees. Die plaaslike gemeente het eintlik geen ander identiteit as sy kontekstuele identiteit nie. Daar is nie 'n ander kerk as die empiriese kerk nie. Daar is wel teoreties 'n ander ideaal vir die kerk, die sogenaamde gedefinieerde subjek ${ }^{19}$. Solank maar erken word dat die voorbeelde wat ons hiervan het ook die kontekstuele beskrywing is van 'n ander empiriese subjek so lank terug as die gemeentes in die Nuwe Testament.

Die plaaslike gemeente het eintlik ook geen ander relevansie as sy plaaslike relevansie nie. Geen ander integriteit en geloofwaardigheid as sy kontekstuele geloofwaardigheid nie. Alle ander geloofwaardigheid rus op kontekstuele missionêre geloofwaardigheid ${ }^{20}$. Die gemeente is eksistensieel tot kontekstualiteit verbind ${ }^{21}$.

As gawe van God aan die wêreld is die gemeente missionêr te verstaan. God is vir altyd aan die wêreld as sy skepping verbonde ${ }^{22}$. Hy het Hom met heil, hulp en hoopgewing aan die wêreld verbind: kerkmatig verbind. God is weliswaar nie kerkmatig beperk in die sin dat Hy niks 
buite die kerk om kan doen nie ${ }^{23}$. Hy kan en doen dit inderdaad. Regerings is byvoorbeeld soms meer besorg oor arm mense en armoede as baie denominasies in die dieselfde land. Nie kerklike instansies is soms meer ekologies sensitief as die mense met die Bybel; meer op soek na reg en geregtigheid as die mense van die Koning van die reg. Mense met die regte Koning gee soms minder om vir die reg van die Koning as wat ander wat die Koning verwerp hulle beywer vir die reg van die reglose. God se bedoeling is wel dat die gemeente hierin die eksperimentele tuin (Bosch) van sy bemoeienis in Christus moet wees: "If it is Christ-centered, the missionary activity of the church will be wholistic as was Christ's own; Christian mission addresses both the spiritual and the physical needs of human beings" 24 .

Die kerk is missionêr te verstaan in die sin dat dit deel is van God se plan om heel te maak wat sonde hier geskend het. Die kerk is deel van God se "ja" vir die wêreld25. Die kerk neem deel aan die missio Dei, gee uitdrukking daaraan. Die missiones ecclesiae is juis spesifieke maniere waarop die gemeente kontekstueel deelneem aan die missio Dei. Die kerk voor die asem van die almagtige, die Pinksterkerk, sê God agterna, doen God agter na, neem instemmend en gewillig deel aan die missionêre betrokkenheid van God by die wêreld, "The missio Dei institutes the missiones ecclesiae" 26 .

Dit is juis hierdie laaste dimensie wat dit onmoontlik maak om die kerk anders as missionêr te verstaan. Die identiteit van die kerk is 'n missionêre identiteit ${ }^{27}$. Die trinitariese verstaan van die kerk dra hierdie missionêre identiteit van die gemeente: "The nature and mission of the church are grounded in the nature and mission of the triune God"28. Die Vader, Seun en Heilige Gees is by die skepping heelmakend betrokke. Namens Hom (in sy Naam) neem die mense van God (gemeente) kontekstueel hieraan deel. Die gemeente is so gesien 'n plaaslike beweging van God Drie-enig. Hier, as deel van die gemeente, sou jy die mense soek wat plaaslik deelneem aan die heelwording van die betrokke gemeenskap en omgewing ${ }^{29}$. In die gemeente sentrum het jy die streekkantoor van God. Hier word die medewerkers in hulpverlening en hoopgewing se werk gekoördineer en georganiseer. Hier mag hulle byvoorbeeld, binne 'n missionêre verstaan van die gemeente, nie so besig gehou word dat hulle aan die gemeenskap onttrek word nie. Wanneer die gemeenskap nie heel word nie, word die gemeente ook siek - al is dit telkens nog 'n miernes van bedrywighede, "When the church is in the world, God is in the church" (Callahan). Bosch noem dit "living in the creative tension of, at the same time, being called out of the world and sent into the world, it (die gemeente 
$M N$ ) is challenged to be God's experimental garden on earth, a fragment of the reign of God" ${ }^{30}$. Gepreokkupeerdheid met die "organisasie sentrum" is 'n teken van verval en burokratisering van die kerk ${ }^{31}$.

Binne ' $n$ missionêre verstaan van die gemeente val alles, elke bediening, in plek en vind lidmate vreugde. Wanneer die gemeente missionêre verlossing vind daardeur om dinge te doen asof dit 'n doel op sigself is, vind die gemeente heil. En ontdek die gemeente dat "it is in giving that we are receiving" 32 .

Die gemeente is dus nie by die missionêre, as nog 'n bediening, betrokke nie. Die gemeente is die missionêre agent van God, in wese, maar ook in en deur alles wat hy doen. Die gemeente geniet intens wat hy doen, byvoorbeeld in die erediens, omdat hy sy missionêre identiteit verstaan en verstaan hoe die erediens daarby inpas en hierdie identiteit dien ${ }^{33}$. Die gemeente is die evangelis en daar is iets wat elke lidmaat kan doen om die gemeente in hierdie missionêre bestaanswyse te help ${ }^{34}$. Waar hierdie perspektief byvoorbeeld gemis word (en die missionêre as een van die take voorgestel word) loop baie dinge verkeerd. Jy skep 'n lidmate korps waarvan sommige dit regkry om "teen die sending te wees" - 'n egte terminus in contradictio. Meer nog: ander lidmate wat wel hierdie identiteit ernstig neem, laat hulle oplei vir sending en evangelisasie. Byna uit reaksie begin hulle "uitreik". Hulle reik egter meer in na ander lidmate as uit na die nie-christelike wêreld. Hierdie "uitreik" word op 'n eie wyse teologies gerasionaliseer: “ons moet na hulle 'uitreik', want al is hulle lidmate was hulle nog nooit werklik wedergebore Christene nie”. Wat gewoon intensiewe bediening, ook ' $n$ bediening van dissipline, moes wees, word tot missionêre bediening verklaar. Talle publikasies (ook uit betroubare oorde) oor die vernuwing van die gemeente dra hierdie gees. Selfs in 'n 1996 publikasie van die bekende Loren Mead word "becoming an apostolic people" as vyfde uitdaging van die toekomstige kerk genoem ${ }^{35}$. Hoe waar dit ook al is, is my indruk steeds dat dit 'n gebrek aan insig in die missionêre identiteit van die gemeente verraai.

\subsection{Roeping vervulling en doeltreffendheid}

Hierdie verstaan van die missionêre identiteit van die gemeente het ernstige konsekwensies vir roepingvervulling. Een daarvan moet hier bespreek word: Sommige gemeentes jaag miskien doeltreffendheid (effektiwiteit) na met sukses as doel. Hierteen kan met reg beswaar gemaak word ${ }^{36}$. Om aan die ander kant te beweer dat missionêre gemeentes nie doeltreffendheid najaag nie, is eweseer 'n dwaling. Missionêre gemeentes word gedryf deur 'n intense bewussyn van God se teenwoordigheid. Juis hierdie bewussyn 
maak sodanige gemeentes sensitief vir hoe hulle hulle roeping vervul: op 'n slordige, mag dit tref manier, of op 'n stylvolle, doelgerigte en doeltreffende manier. Die vraag van 'n missionêre gemeente is nie eerstens wat is die minimum waarmee ek kan wegkom nie, maar hoe gee ons die maksimum op so 'n wyse dat ons plaaslik in die Naam van God 'n egte koninkryksverskil maak? Die missionêre gemeente is, weliswaar om 'n ander rede, nie minder effektiwiteitsbewus as die sukses gedrewe gemeente nie. So 'n gemeente is nooit met minder as die beste in diens van sy roeping vervulling tevrede nie. Missionêre gemeentes is gewoonlik ook nie bang om hulle funksionering te evalueer nie. Om in die Naam van God ' $n$ verskil in en aan 'n samelewing te maak, is 'n saak van die verheerliking van God. En vir die kerk is dit belangrik. 'n Diepliggende teologiese rede vir hierdie vryheid is juis dat die missionêre gemeente lank nie meer deur vrees vir voortbestaan gedryf en beheers word nie. Binne die missionêre verstaan van die gemeente vind gelowiges rus in die belofte van God wat self sy kerk in stand hou. Gekonfronteer met sy taak en met sy teenstanders vra die gemeente nie eerstens na sy oorlewing nie. Die oorlewing van die missionêre gemeente is nie ter sprake nie. Die kern vraag bly hoe so 'n gemeente op 'n gegewe tyd en plek, onder gegewe omstandighede getrou aan sy bestaansdoel funksioneer ${ }^{37}$ ?

Een van die mees voor die hand liggende byvoordele van 'n missionêre verstaan en bestaanswyse van die gemeente is die geestelike insig en onderskeidingsvermoë van die koringkorrel wat in die grond val, sterf en vrug dra (Joh 12). Die gemeente ontwikkel weer 'n geloofsperspektief op homself. Dit blyk ' $n$ ingeboude swakheid van die instandhouding motief te wees dat dit die gemeente van 'n geloofsuitsig op homself beroof.

\section{KONSOLIDEREND EN MISSIONEREND}

Uit die eksegese van die Efese brief is dit duidelik dat die gemeente se opbou midde in die wil van God is. Hierdie opbou is altyd twee dinge tegelyk: die "stene" wat reeds in die muur is, word konsoliderend versorg EN die "stene" wat nog nie in die muur is nie word bygebou. Dit is immers die voor die hand liggende betekenis van die bou-metafoor. Dit is opsigself duidelik. Wat meermale nie so deursigtig is nie, is dat hierdie twee "bewegings" gelyktydig gebeur. Die een gebeur terwyl die ander gebeur. Die een kan nie sonder die ander gebeur nie. Indien die een nie gebeur nie, gebeur die ander ook nie. Die twee is interafhanklik en staan in 'n kreatiewe spanning tot mekaar ${ }^{38}$. Volgens Roberts stel juis die bou-beeld "die missionêre karakter van die kerk in hierdie bedeling bo alle twyfel" 
Insig in hierdie spanning word gedra deur insig in die missionêre identiteit van die kerk. Vir gemeentes wat oor jare heen binne 'n instandhoudingmodus gefunksioneer het, is dit moeilik. Dit voel na verlies aan identiteit en is traumaties. 'n Verandering van konsolidering alleen en opsigself tot konsolidering en missionering tegelyk òf van eers konsolidering en dan missionering (of andersom) beteken niks minder as 'n ekklesiologiese bekering nie. Laasgenoemde is juis nie moontlik sonder 'n diepgaande verandering in verhouding met die lewende God self nie ${ }^{40}$. Doelvinding in gemeentebou is dus geen eenvoudige saak nie. Dit is pynlik. Dit is een rede waarom die eerste fase van die proses (identiteit vinding) ook as "ontvriesing" beskryf word ${ }^{41}$. Vir talle gemeentes in die instandhoudingmodus is dit niks minder as 'n geloofsprong nie.

Missionêre identiteitvinding is bevrydend. Om baie redes, maar ook en veral omdat konsolidering sin begin maak en die gemeente dit begin geniet. Die gemeente vind plek in die plan van God en in die nood en behoeftes van die omgewing. Verby is die dae van doellose deelname aan programme (selfs die erediens), hier is die dae van sinvolle "opleiding" en menswording onder mede gelowiges wat ons help met menswees in die gemeenskap. Die wêreld word heel en vind heil, God word verheerlik, die Koninkryk kom. Wat meer kan gelowiges vra?

\section{Konkrete Koninkryk soeke}

Missionêre identiteitvinding bring insig, teologiese insig, in die perspektief dat die gemeente deelneem aan die kommunikasie van die evangelie van Christus. Die gemeente vind hierin sy hoogste doel. Deur hierdie evangelie het die gemeente ontstaan en neem nou deel aan die rede vir bestaan. Goeie nuus ontvang, word goeie nuus meegedeel. Hierdie goeie nuus kan gereformeerd gesproke nie maar net eensydig soteriologies verstaan word nie. Die evangelie van Jesus is die evangelie van die Koninkryk (Luk 8:1). Dit is hierdie konkretisering van die goeie nuus wat die missionêre identiteit en doel van die gemeente so opwindend maak: siekes word gesond, kreupeles loop weer, blindes sien, hongeriges vind brood, 'n daklose 'n dak, regloses vind die reg, mense gebind deur verslawing word vry, mense met skuld vind vergifnis en skenk vergifnis, mense in konflik vind versoening en neem deel aan die versoening, mense wat die dood vrees vind die lewe wat ewig is, ensovoorts. Die kreatiewe moontlikhede in die soek na die koms van hierdie ryk is die kontekstuele uitdaging van elke gemeente. Hierdie moontlikhede hou konkreet verband met die behoeftes van die gemeenskap waar die gemeente deelneem aan sy missionêre doel ${ }^{42}$.

Konsolidering vind nuwe sin binne die verstaan van die ritme van "albei altyd tegelyk". Om jou eie konsolidering as gemeente as 'n ter wille 
van te verstaan, is bevrydend - so bevrydend as wat dit vir 'n koringkorrel is om in die grond te val, te sterf en vrug te dra. Die gemeente word so tot doelvinding bevry, tot vrugdra verlos. Die gemeente se tussen-tydelikheid word nie langer as bedreiging beleef nie, maar as deel van sy identiteit geniet.

Juis hierdie insig in die missionêre identiteit van die gemeente, bring ook nuwe waardering vir die gemeente in kerk verband - denominasioneel en ekumenies. Dit is die missionêre gemeente wat verstaan dat die totale kerk aan die wêreld geskenk is tot diens en heil. Geen gemeente is opsigself, alleen die volle kerk nie. Om as gemeente ten volle kerk te wees, beteken immers nie dat elke gemeente die volle kerk in enige gemeenskap is nie - tensy so 'n gemeente nog die enigste kerk in daardie gemeenskap is. Die eenheid van die kerk maak slegs sin en word slegs ernstig geneem wanneer 'n missionêre bewussyn groei. Laasgenoemde gebeur wanneer gemeentes die missionêre identiteit van die gemeentes verstaan en dit in die kerk verband indra. Die geskiedenis van die N G Kerk is hiervan 'n onbetwisbare bewys. 'n Missionêre denominasie wat sendelinge na die uithoeke van Afrika gestuur het, was nie noodwendig 'n bewys dat die gemeentes van hierdie verband hulleself as missionêr verstaan het nie. Die reaksie op die missionêre deurbraak wat in Kerk en Samelewing (1986) beleid geword het, was nie slegs polities van aard nie. Dit was ook 'n bewys dat missionêre denominasionele beleid nie van bo-af gemeentelike identiteit voortbring nie. Laasgenoemde het met die verdieping van die gemeente se verstaan van God te doen en nie met die diepte van voorspoedige mense se beursies nie en wat gebeds- en beursie-matig aan buitelandse sending deelneem nie. 'n Gemeente kan sendelinge stuur sonder om gestuurdes te wees. 'n Gemeente kan selfs sy missionêre identiteit ontken deur eensydig met buitelandse sending besig te raak. Soms is dit ontvlugting van die konkrete en kontekstuele eise van die evangelie van die gekome en komende Ryk van God. Die kontekstuele uitdagings vir die konkrete deelname aan die komende Ryk is meermale kultureel en andersins ongerieflik. Om te bid vir dit wat elders gebeur (of nie gebeur nie) is geriefliker as betrokkenheid by die nuwe en lastige uitdagings van en in die onmiddellike omgewing. Weer eens: kontekstuele geloofwaardigheid is hier op die spel. Elke gemeente het hiervoor ondersteuning en ook 'n ekklesiologiese gewete nodig. Die kerkverband kan in hierdie behoeftes voorsien.

\section{5}

SAMEVATTEND

Die gemeente is nie 'n funksie van die apostolaat nie. Die gemeente is wel 'n funksie van sy missie (bestaansdoel). Die bestaanswyse en funksionering 
van die gemeente is missionêr (apostolêr) in wese en aard. Die toets hiervoor is of die wêreld die plaaslike gemeente as sodanig beleef. Nie of almal (al) daarby inskakel nie, maar of dit die beeld is wat hulle van die kerk het: hier word namens die God wat hulle (die gemeente) bely, deelgeneem aan dit wat hulle bely hulle God mee besig is.

Wanneer konsolidering en missionering tegelyk as doel van gemeentebou gehandhaaf word, behoort dit die uitkoms te wees. Hiermee is meteens ook bely dat konsolidering en missionering ook nie as sodanig (asof dit iets abstrak is) doel van gemeentebou is nie. Geen gemeente word in hierdie opsig teoreties gebou nie. In gemeentebou word beide vasgehou en nagejaag, want alleen so vervul die gemeente sy roeping voor God, teenoor mekaar en binne die wêreld. Sò neem die gemeente onder die beheer van die Gees deel aan dit waarmee God Drie-enig besig is.

\section{NOTAS:}

1 M Nel, Gemeentebou, Halfway House 1994, 21.

2 M te Velde, Gemeenteopbouw 1, Bameveld 1992, 18-28; H L Green, Why churches die, Minneapolis 1972, 15 vv; Nel, $a w, 1994,16-19$.

3 Vergelyk die massa publikasies wat gerig is op die vernuwing van die gemeente. By al die ander waarna nog hieronder verwys word, word die volgende hier genoem: B Hull, 7 Steps to transform your church, Grand Rapids 1993; L E Schaller, Tattered trust (is there hope for your denomination), Nashville 1996; R M Oswald \& R E Friedrich (jr), Discerning your congregations future, New York 1996; C J Woods, Congregational mega trends, New york 1996; D E Miller, Reinventing American Protestantism, Berkeley 1997; H Miller (ed), Unlocking church doors (10 keys to positive change), Nashville 1997.

4 F M Dubose, How churches grow, Nashville 1978, 146; J M Corbett \& C E Johnson, A design for church growth, New York 1972, 3; M Nel, “Die Opbou van die gemeente", Skrif en Kerk 3/2 (1982), 42-48.

5 Te Velde, $a w, 27$; Vergelyk ook J B Cobb jr, Reclaiming the church, Louisville 1997; D A Roozen \& C K Hadaway (eds), Church and denominational growth, Nashville 1993.

6 Vergelyk A König, Vernuwe of verdwyn, Kaapstad 1998, 61.

7 E Gibbs, Winning them back. Tackling the problem of Nominal Christianity, Tumbridge Wells 1993, 97.

$8 \quad$ König, $a w, 1998,103$ vv.

$9 \quad$ König, $a w, 1998,25$.

10 K L Callahan, Visiting in an age of mission, San Francisco 1994, 14.

11 J M Corbett \& C E Johnson, A design for church growth, New York 1972, 3.

12 Vergelyk J Kiernan, "From opposition to mutual accomodation" in: $M$ Prozesky (ed), Christianity in South Africa, Bergvlei 1990, 9-27; M Prozesky, "Implications of Apartheid for Christianity in South Africa" in Prozesky, $a w$, 1990, 122-148; J Gonzalez, The story of Christianity Vol 1, San Francisco 1984; Vol 2, 1985; J Comby, How to read church history, London 1985. In 
hierdie verband is die boek van Mark Shaw ook van belang: M Shaw, 10 great ideas from church history, Downers Grove 1997. Vergelyk ook die besondere bydrae van W Jonker, Selfs die kerk kan verander, Kaapstad 1998.

13 Vergelyk in hierdie verband die deeglike navorsing van G A Rekers, Pastoral modes in a Theology of Evangelism (Ongepubliseerde DTh proefskrif), Unisa 1997; Ook R W Johnson, How will they hear if we don't listen, Nashville 1994; S Sjogren, Conspiracy of kindness, Ann Arbor 1993.

14 J Hendriks, Een aantrekkelijke gemeente, Kampen, 1990; K A Schippers, “Als de gemeente subjekt wordt...”, Praktische Theologie 10/3 (1983), 284-297. Nel, $a w, 1994,21 \mathrm{vv} ; 125 \mathrm{vv}$.

16 Ibid.

17 Vergelyk in hierdie verband L A Drummond, The word of the cross. A contemporary theology of evangelism, Nashville 1992, 98-202; C E Gunton, The promise of Trinitarian theology, Edinburgh 1991, 1-30; D L Migliore, "The missionary God and the missionary church", The Princeton Seminary Bulletin XIX/1 (1998), 14-25; M Nel "Building up a missionary local church" in: C J A Vos (ed), Proclaim the Gospel, Pretoria 1993, 130-148.

18 Vergelyk die besondere bydrae in hierdie verband van C S Dudley \& E Hilgert, New Testament tensions and the contemporary church, Philadelphia 1987.

19 K A Schippers, "Werken aan de gewone gemeente 1", Praktische Theologie 2 (1982), 96-105.

20 Vergelyk die bespreking van die teenstelling plaaslike en "foreign missions" in Bosch, $a w, 10$. Hy is myns insiens korrek wanneer hy stel dat die verskil nie 'n prinsipiële een is nie, "but of scope". My beklemtoning in hierdie artikel is bedoel om die missionêre bestaanswyse as 'n kontekstuele werklikheid te beklemtoon.

21 L J Luzbetak, Tha church and cultures. New perspectives in missiological anthropology, Maryknoll 1990, veral 12-63; G G Hunter III, How to reach secular people, Nashville 1992, 135-171; G Dekker, D A Luidens, R R Rice, Rethinking Secularization (Reformed reactions to modernity), Lanham 1997; Vergelyk ook D J Hesselgrave \& E Rommen (eds), Contextualization (meanings, methods, and models), Grand Rapids 1989. Veral sy beskrywing van "contextualization that is authentic and relevant", 199-201; C H Kraft, Christianity in culture, Maryknoll (10) 1992.

22 Vergelyk I J du Plessis, "Die God wat skep en herskep - ekologie en menseverhoudinge in Kolossense", Skrif en Kerk 12/2 (1991), 194-213; A König, Bondgenoot en Beeld, Halfway House 1988, 1-107.

23 Vergelyk byvoorbeeld J A Heyns, Dogmatiek, Pretoria 1978, 352-389.

24 Migliore, $a w, 1998,19$.

25 D J Bosch, Transforming Mission. Paradigm shifts in Theology of mission, Maryknoll 1991, 10.

26 Bosch, $a$ w, 1991, 370; Vergelyk A A van Ruler, Theologisch Werk 1, Nijkerk 1969, 175 ev; Theologisch Werk IV, Nijkerk 1973, 9 ev.

27 C van Engen, God's missionary people. Rethinking the purpose of the local church, Grand Rapids 1991, 25-132.

28 Migliore, $a w, 1998,17$. 
29 Vergelyk J $R$ Hendrick, "Congregations with missions vs missionary congregations" in: G R Hunsberger \& $\mathrm{C}$ van Gelder (eds), Church between Gospel and Culture, Grand Rapids 1996, 298-307.

30 Bosch, $a w, 11$.

31 Vergelyk H J C Pieterse, "Burocracy in the reformed tradition in South Africa", Journal of Theology in Southern Africa 43 (1983), 55-64; Nel, a w, 1994, se verwysing na Hoekendijk.

32 Vergelyk G R Hunsberger, "Aquiring the posture of a missionary church" in: G R Hunsberger \& C van Gelder (eds), Church between Gospel and Culture, Grand Rapids 1996, 289-297.

33 K L Callahan, Dynamic Worship. Mission, grace, praise, and power, San Francisco 1994, 3-10, 143-153. Vergelyk ook M Nel, "Die erediens en die wêreld" in: A J Smuts, C J A Vos, M Nel (reds), In gesprek oor die erediens, Pretoria 1990, 172-192.

$34 \quad$ R S Armstrong, Service Evangelism, Philadelphia 1979, 38-50.

35 L B Mead, Five challenges to the once and future church, New York 1996, 6980. Vergelyk ook J E White, Rethinking the church, Grand Rapids 1997, 38-52.

36 Baie literatuur wat met Gemeentebou geassosieer word, dra na my oordeel te veel hierdie sukses gedrewe "effektiwiteitsdrang". Voorbeelde is: T S Rainer, Eating the elephant, Nashville 1994; T Rainer, Effective evangelistic churches, Nashville 1996. In beide bronne is daar geen aanduiding van wie die objek van "outward focus" is nie. Vergelyk Rainer, $a w, 55$. Nog voorbeelde is: T Campolo, Can mainline denominations make a come back, Valley Forge 1995, Vergelyk veral 185-196; J Russell, Awakening the gaint, Grand Rapids 1996, 27-40. Vergelyk vir nog 'n perspektief hierop veral L B Mead, More than numbers: the way churches grow, New York 1993.

37 Nel, $a w, 1994,21-25$.

38 Nel, $a w, 5-14$ en die verwysings na verskeie Nuwe Testamentici.

39 J H Roberts, Nuwe Testamentiese perspektiewe op die opbou van die kerk, (SEVTO lesing), 1985, 6.

40 Armstrong, $a w, 1979,16$.

41 Nel, $a w, 1994,125-144$.

42 Bydraes wat in hierdie verband krities belangrik is, is: $\mathrm{R} \mathrm{S}$ Armstrong, $a w$ 1979; C S Dudley (ed), Building effective ministry, New York 1983; H M Conn, A clarified for urban mission, Grand Rapids 1987; J J Kritzinger, P G J Meiring, W S Saayman, On being witnesses, Halfway House 1994; B Johnson, New day new church, Decatur 1995; M J Coalter \& V Cruz (eds), How shall we witness (Faithful evangelism in a reformed tradition), Louisville 1995; P U Maynard-Reid, Complete evangelism (the Luke-Acts model), Waterloo 1997; M Nel, "Service Evangelism: The theology and methodology of a lifestyle", Journal of the Academy for Evangelism in Theological Education 13 (19971998), 31-42. 